\title{
Oligonucleosides with Integrated Backbone and Base: Foldamers with a Novel Architecture
}

\author{
Andrea T. Vasella*
}

\begin{abstract}
Dinucleoside and tetranucleoside analogues with integrated backbone and nucleobase represent a novel type of oligonucleotide foldamers. They are characterized by a linker between $\mathrm{C}\left(5^{\prime}\right)$ of one nucleoside moiety and $\mathrm{C}(8)$ of an adjacent adenosine, or C(6) of an adjacent uridine. Solutions in chloroform or chloroform/DMSO of these partially protected di-, or tetranucleoside analogues associate. The strength of the association depends on the nature of the linker, the presence, or absence of a hydroxymethyl group on the terminal nucleobase, other protecting groups, and intramolecular hydrogen bonds. The thiomethylene-linked dimers were studied in detail; one of them associates strongly enough that a melting temperature can be determined, evidencing base stacking in chloroform solution. Some dimers form organogels. Two $2^{\prime}, 3^{\prime}-\mathrm{O}$-isopropylidene protected self-complementary tetramers were prepared. Their duplexes are conformationally homogeneous. One of the tetramers was characterised in detail; it associates via hydrogen bonds of the Watson-Crick type to form a partial A-type helix with all bases in a synconformation and a rather large twist angle. Also studied were di- and tetranucleotide analogues possessing an all-carbon linker; they were derived from (hydroxy)propynylene linked dimers by deoxygenation, partial reduction to the (E)- and (Z)-propenylene linked analogues, and further hydrogenation to propanylene-linked analogues. The propargylic hydroxy group forms an intramolecular hydrogen bond to $\mathrm{N}(3)$ of the adenine moiety of the same unit; the resulting conformers associate weakly. Deoxygenation leads to foldamers that associate much more strongly. A (Z)-propenylene-linked dimer also associates strongly, its $(E)$ isomer less so, and the propanylene-linked analogues associate weakly. The results show that backbone-base integration defines a novel structural relation between backbone and nucleobases that favours selective pairing and leads to oligonucleotide foldamers.
\end{abstract}

Keywords: Hydrogen bonding · Oligonucleoside foldamers · Pairing $\cdot$ Stacking

\section{Introduction}

The strongest motives for the design and synthesis of oligonucleotide mimics have been the search for antisense or antigene activities [1-14] and the quest for a rational insight into the prebiotic origin of nucleic acids [15]. They led to the synthesis of numerous analogues, modifying nucleobases, ribose or deoxyribose units, and the phos-

\footnotetext{
${ }^{*}$ Correspondence: Prof. Dr. A.T. Vasella

Laboratorium für Organische Chemie

ETH-Hönggerberg

Wolfgang Paulistrasse 10

$\mathrm{CH}-8093$ Zürich

Tel.: +4144632 5130

Fax: +41446321136

E-Mail: vasella@org.chem.ethz.ch

http://avws-indi2.ethz.ch/
}

phodiester linkage. Peptide nucleic acids ([16-23] and earlier papers) even do away with the monosaccharide and the phosphate moieties. However, as a consequence of these goals, the essential architecture of nucleic acids - the structural differentiation between a contiguous backbone and nucleobases attached to it - has always been maintained. There are no obvious reasons why the structural differentiation between backbone and nucleobases should be an absolute requirement for a base- and sequence-specific mutual recognition of oligonucleotide mimics by hydrogen bonding and base stacking, i.e. for the formation of autonomous pairing systems.

Considering the relevance of information encoding, storage, and transmission, and impressed by the variety of secondary structural elements and functions of RNAs [5] [24-30] and references quoted there) we set out to experimentally test the contention that oligonucleotide foldamers where the nucleobases are integrated into the backbone (Fig. 1) may associate via hydrogen bonding, maintain base stacking, show se- quence specific recognition, and form welldefined secondary elements.

Incorporating the nucleobases into the backbone means linking the nucleobases through $\mathrm{C}(2)$ or $\mathrm{C}(8)$ of purines, and $\mathrm{C}(5)$ or $\mathrm{C}(6)$ of pyrimidines (Fig. 1). A choice between these locations was made on the basis of rather straightforward modelling, starting with B-DNA, removing in silico all elements, except the bare nucleobases interacting via Watson-Crick hydrogen bonds, and introducing possible linkers at the indicated positions of adenosine and uridine [31]. The structure of the resulting oligomers was relaxed by energy minimisation and the characteristics of the resulting helix, stacking, and hydrogen bonding were compared. This led to a number of possible foldamers and to somewhat more promising structures if $\mathrm{C}(6)$ of pyrimidines and $\mathrm{C}(8)$ of purines were chosen as point of attachment for the various linkers under consideration.

While the question of possible applications of such foldamers has to be asked, it appeared premature to give specific an- 

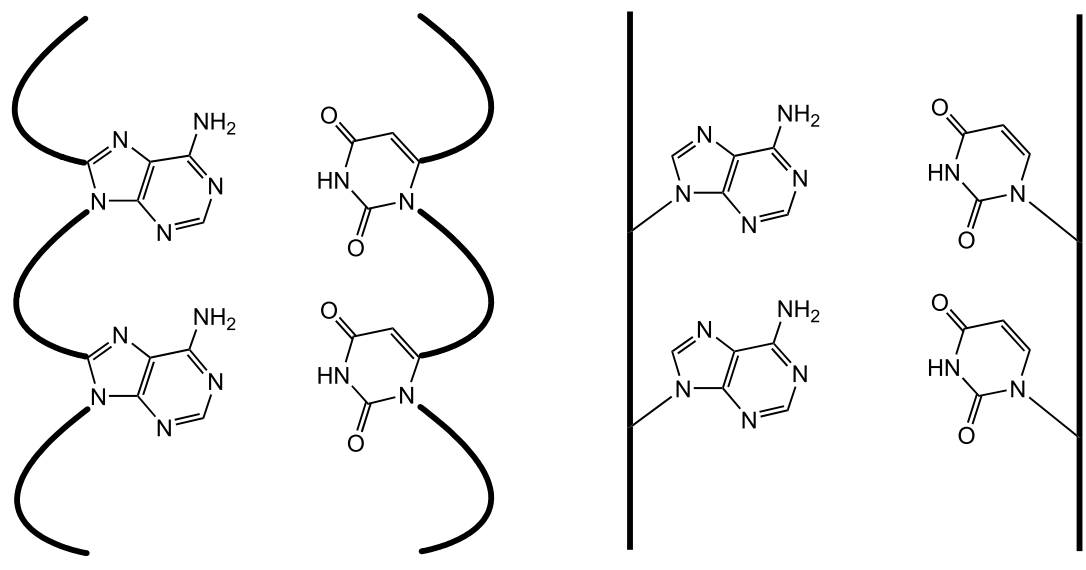

A

B

Fig. 1. Base/backbone integrating foldamers $\mathbf{A}$ and base/backbone differentiated oligonucleotides and analogues $\mathbf{B}$

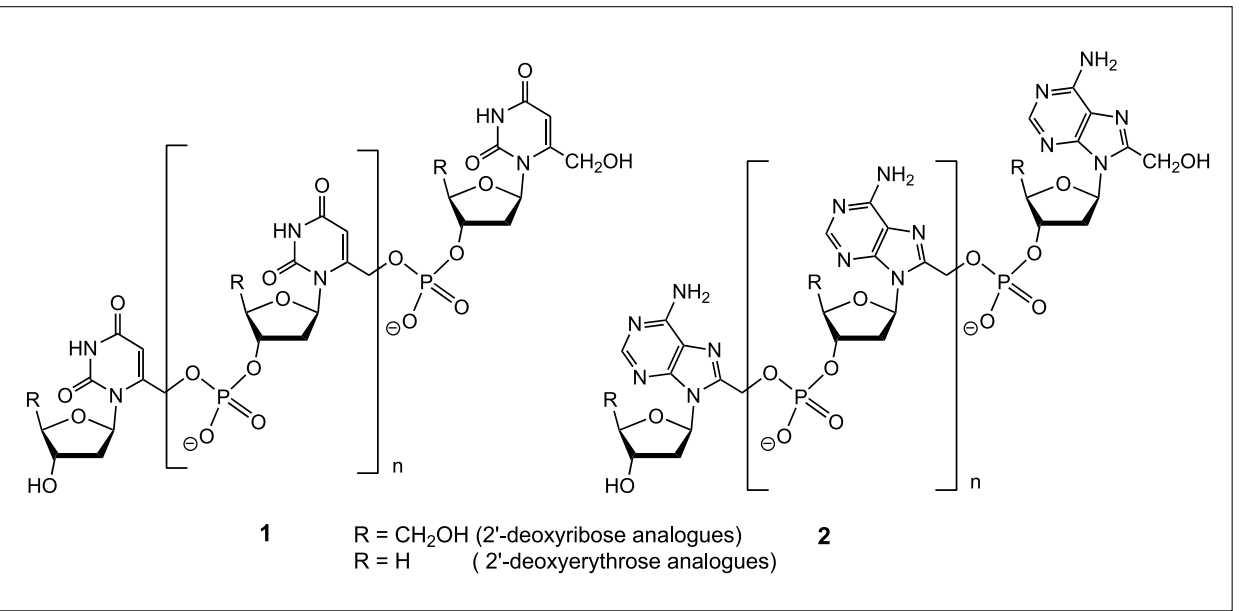

Fig. 2. Phosphodiester analogues 1 and 2

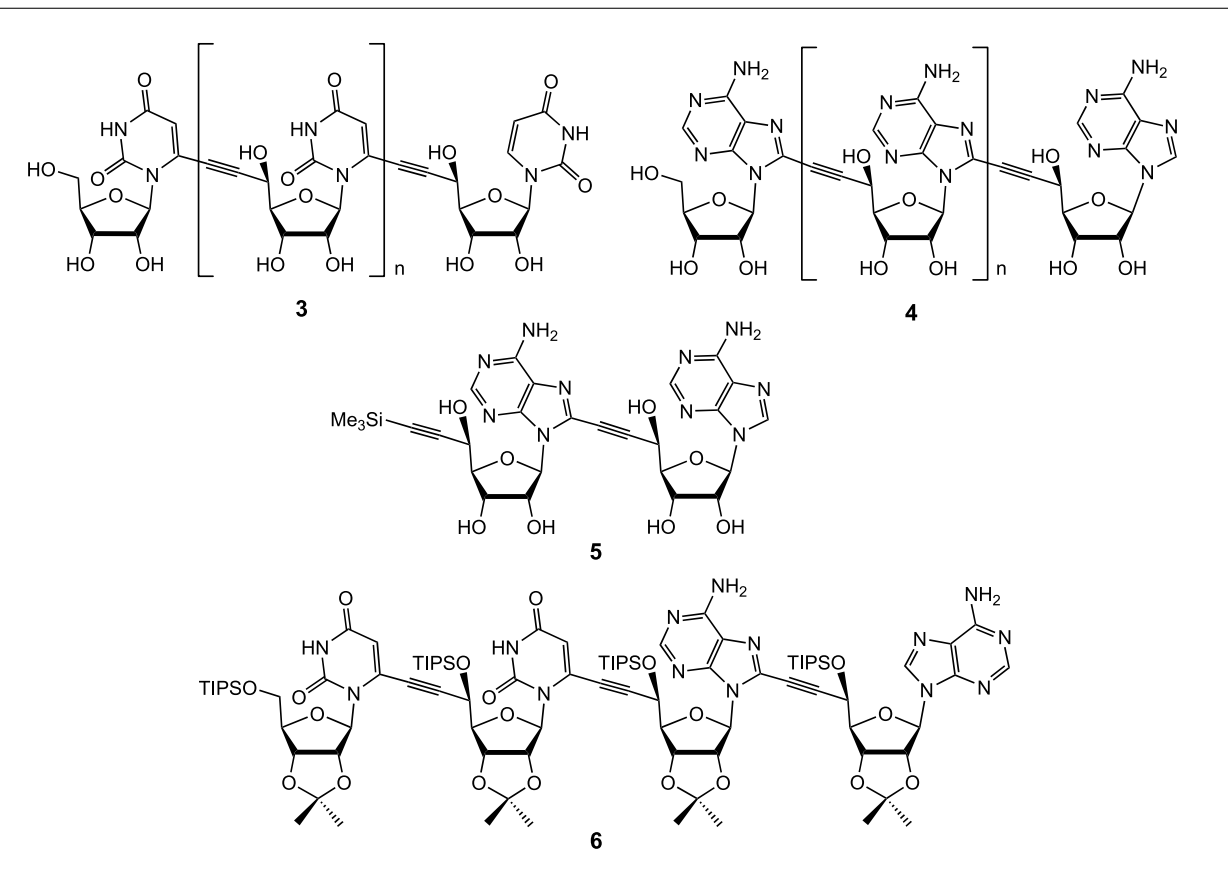

Fig. 3. Ethynylene-bridged oligonucleosides $\mathbf{3}$ and $\mathbf{4}$ swers. The search for novel foldamers and their properties is a discovery programme rather than one based upon invention. While it is necessary to choose a fruitful field for such a programme, it is by definition impossible to predict the nature of discoveries to be made. However, possible applications will be similar to those of other self-associating systems that shape space, and pertain to the domain of material sciences, nanotechnology, catalysis, and biology [22][32-38]. Biological applications (interference with nucleic acids, proteins, or glycoconjugates) will depend upon the interactions of such foldamers with nucleic acids and/or proteins and require a sufficient degree of water solubility.

Before evaluating any applications we have to show that such a fundamentally altered architecture of oligonucleotide foldamers is compatible with the desired properties. To demonstrate that nucleic acids can be modified more extensively than so far explored and yet show specific recognition and form specific secondary elements appeared sufficiently important to embark on the synthesis of backbone/ base integrating oligonucleotide analogues.

\section{Results and Discussion}

In the following I will summarise the results of our first steps towards such analogues, leading to a proof of principle.

The first foldamers we aimed at are the decamers 1 and $2(n=8)$ (Fig. 2), incorporating adenosine $(\mathrm{A})$ and uridine $(\mathrm{U})$ only [39]. As A and U can only associate via two hydrogen bonds, pairing of such foldamers would constitute a more stringent proof of concept. A solid-phase synthesis provided the protected 10 mers $\mathbf{d U}^{*}{ }_{\mathbf{1 0}}$ and $\mathbf{d A} \mathbf{*}_{\mathbf{1 0}}$. While $\mathbf{d U} \mathbf{*}_{\mathbf{1 0}}$ was successfully deprotected, attempted deprotection of $\mathbf{d A}^{*}{ }_{10}$ under a variety of conditions led to strand break, rationalised by a facile elimination triggered by $\mathrm{N}$-debenzoylation. This persistent problem led us abandon these mimics.

In a parallel effort we synthesised RNA analogues of type 3 and 4 (Fig. 3). An ethynylene-linked uridine-derived hexamer and an adenosine-derived tetramer were obtained by a linear and/or convergent approach, including oxidation of the $\mathrm{C}\left(5^{\prime}\right)$ hydroxymethyl to a formyl group, a diastereoselective addition of an ethynyl zinc or magnesium reagent, and Sonogashira coupling to a $\mathrm{C}(8)$ bromo or iodo nucleoside [40-42]. As a rule, C(8)-substituted purines and $\mathrm{C}(6)$-substituted pyrimidines prefer the syn conformation, while the design of the oligomers 3 and 4, based upon the structure of B DNA, postulated an anti conformation of the nucleobases. 
We had hoped that the sterically undemanding ethynyl substituent might be compatible with a sufficient population of the anti conformation to allow base pairing. However, conformational analysis of the dimer $\mathbf{5}$ demonstrated a persistent hydrogen bond between the propargylic hydroxy group and $\mathrm{N}(3)$ of the same monomeric unit that is only compatible with a syn conformation [43]. In keeping with this observation, fully deprotected tetramers did not pair in $\mathrm{MeOH}$, while the protected tetramer 6 associated in $\mathrm{CDCl}_{3}$ [41][44]. This suggested to either remove the propargylic hydroxy group, or to design new analogues that pair in a syn conformation.

In view of the demanding synthesis of higher oligomers of type $\mathbf{3}$ and $\mathbf{4}$, we first explored the second possibility. The simplest representative of such analogues were the oxymethylene-linked $\mathrm{U}^{*}$-[o]-U and $\mathrm{A}^{*}$ [o]-A oligomers 7 and 9 (a star denotes a $\mathrm{CH}_{2} \mathrm{X}$ group at $\mathrm{C}(6)$ of $\mathrm{U}$ or at $\mathrm{C}(8)$ of $\mathrm{A}$, and $[\mathrm{x}]$ denotes the element in the linking unit; Fig. 4) [45]. Maruzen model studies and Macromodel V. 4.5 Amber* force-field calculations indicated that the corresponding $\mathrm{U}^{*}-[\mathrm{o}]-\mathrm{U}^{*}$ and $\mathrm{A}^{*}$-[o]- $\mathrm{A}^{*}$ oligomers adopt the $s y n$-conformation and form a parallel right-handed B-helix, characterized by seven residues per turn and Watson-Crick H-bonds at a distance of $2.96 \AA$.

The synthesis of 7 and 9 was based on a $\mathrm{C}\left(5^{\prime}\right) \mathrm{O}$ alkylation by the electrophiles 8 and 10. While 8 formed the desired ethers, the adenosine-derived electrophiles $\mathbf{1 0} \mathrm{did}$ not, presumably due to the facile formation of a cationic intermediate $\mathbf{1 1}$ that already explained the facile strand-break of the decameric phosphodiester 2. Pairing studies were conducted with the accessible dimers in chloroform solution, following the concentration dependent chemical shift of $\mathrm{H}-\mathrm{N}(3)$ of the uridine moiety.

This ${ }^{1} \mathrm{H}-\mathrm{NMR}$ analysis showed that $\mathbf{1 2}$, the self-complementary dimers $\mathbf{1 3}$ and $\mathbf{1 5}$, and their partially deprotected derivatives 14, 16, and 17 do pair (Fig. 5 and Table). The association constants and the thermodynamic parameters show a remarkably strong association in chloroform, entropyenthalpy compensation, and a strong influence of the protecting groups on pairing.

The fully deprotected dimers derived from 12, 13, and 15 did not pair in aqueous solution, suggesting that the association might be due mostly or exclusively to hydrogen bonding.

Although these results constitute a proof of concept for the pairing of this type of foldamers, one may argue that the formation of $\mathrm{H}$-bonds in chloroform is neither a surprise nor much of a proof before the H-bond characteristics (Watson-Crick or Hoogsteen), a 1:1 stoichiometry of pairing, stacking of the nucleobases, and sequence

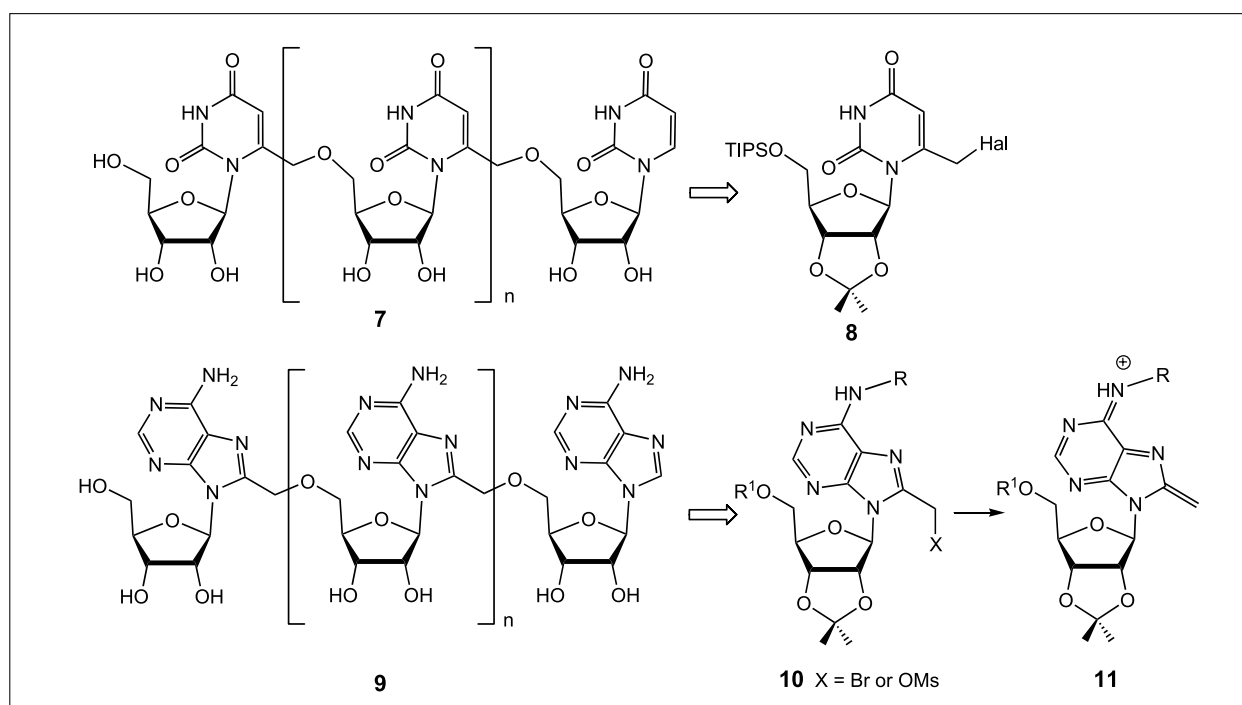

Fig. 4. Oxymethylene-linked foldamers 7 and 9

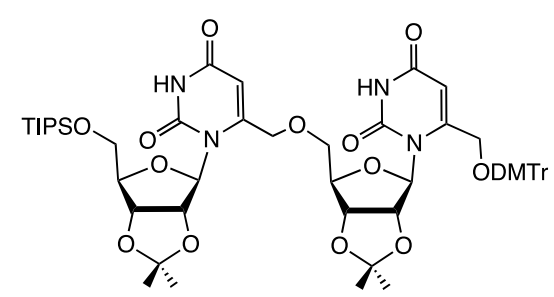

12

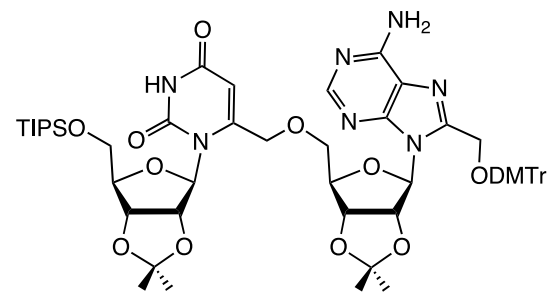

15

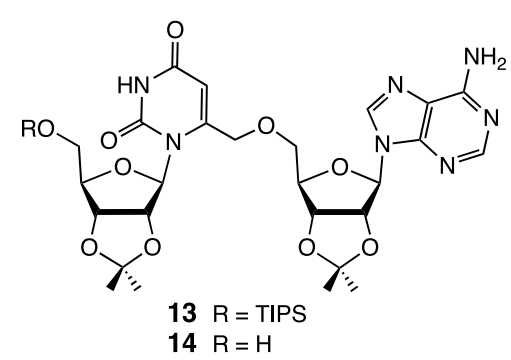

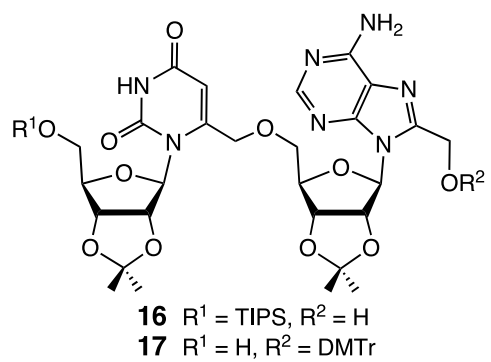

Fig. 5. $U^{*}-[0]-U^{\star}, U^{*}-[0]-A$, and $U^{*}-[0]-A^{*}$ dimers 12-17

Table. Association constants and thermodynamic parameters for the $\mathrm{U}^{*}$-[o]-A dimers 13 and 14, the $U^{*}$-[o]- $A^{*}$ dimers 15-17, and association constant and $\Delta G$ for the $U^{*}-[0]-U^{*} \operatorname{dimer} 12$

\begin{tabular}{lccccc} 
Dimer & $\mathrm{K}_{\mathrm{a}}\left[\mathrm{M}^{-1}\right]$ & $-\Delta \mathrm{H}[\mathrm{kcal} / \mathrm{mol}]$ & $-\Delta \mathrm{S}[\mathrm{e} . \mathrm{u}]$. & \multicolumn{2}{c}{$\left.-\Delta \mathrm{G}[\mathrm{kcal} / \mathrm{mol}]^{\mathrm{a}}\right)$} \\
13 & 1890 & 22 & 62 & 4.0 & 4.4 \\
14 & 2500 & 13 & 30 & 4.6 & 4.2 \\
15 & 970 & 16 & 40 & 4.0 & 3.9 \\
16 & 280 & 22 & 64 & 3.3 & 3.0 \\
17 & 3220 & 24 & 65 & 4.7 & 5.3 \\
12 & 265 & - & - & 3.3 &
\end{tabular}

a) The first value is calculated from $K_{a}$, the second one from $\Delta H$ and $\Delta S$. 


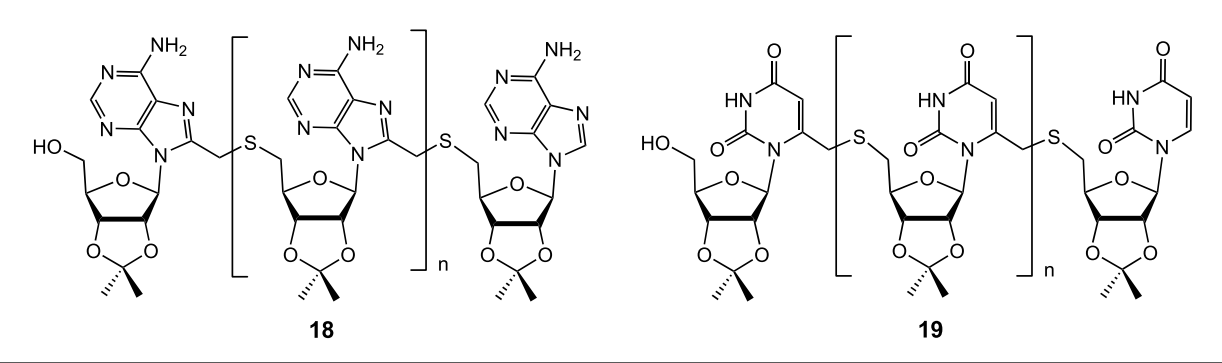

Fig. 6. Thiomethylene-linked oligonucleotide analogues 18 and 19
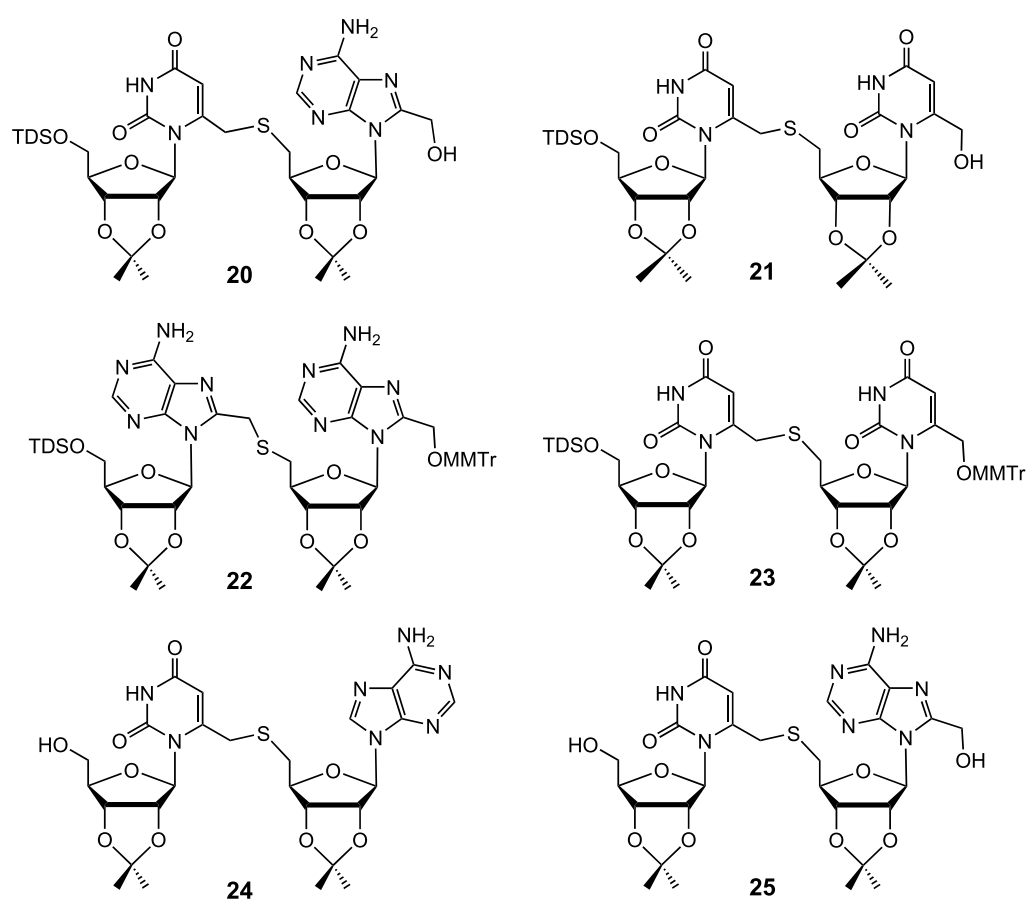

Fig. 7. Selected S-linked dimers 20-25 used for the determination of the association (strength and stoichiometry)
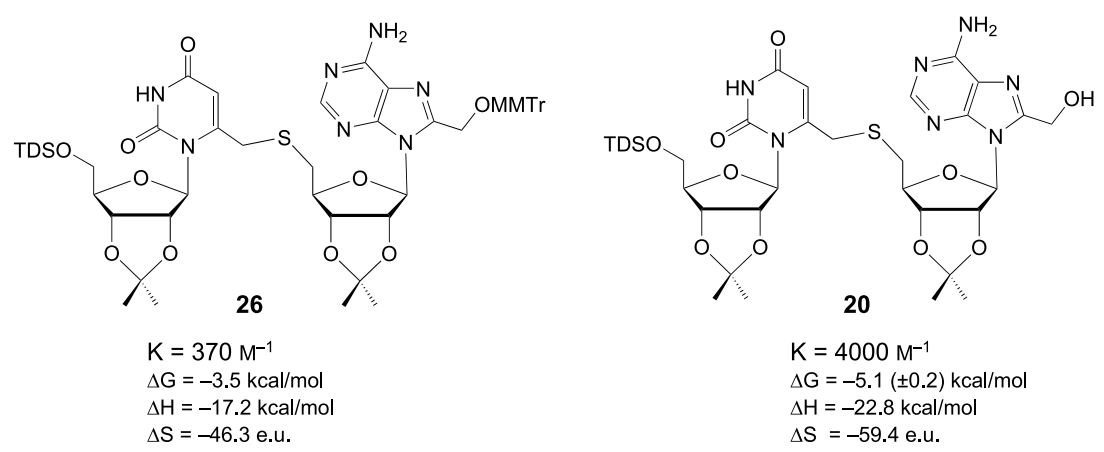

$\mathrm{K}=4000 \mathrm{M}^{-1}$

$\Delta \mathrm{G}=-5.1( \pm 0.2) \mathrm{kcal} / \mathrm{mol}$

$\Delta \mathrm{H}=-22.8 \mathrm{kcal} / \mathrm{mol}$

$\Delta S=-59.4$ e.u.

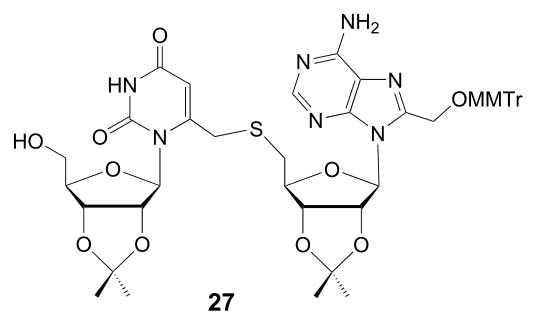

$\mathrm{K}=2900 \mathrm{M}^{-1}$

$\Delta \mathrm{G}=-4.7$ to $-4.8 \mathrm{kcal} / \mathrm{mol}$

$\Delta \mathrm{H}=-17.3 \mathrm{kcal} / \mathrm{mol}$

$\Delta S=-42.2$ e.u.

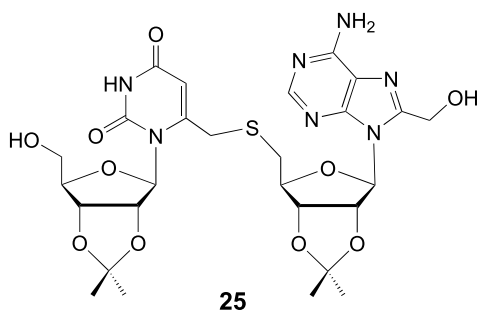

$\mathrm{K}=16000 \mathrm{M}^{-1}$

$\Delta \mathrm{G}=-5.6$ to $-5.7 \mathrm{kcal} / \mathrm{mo}$

$\Delta \mathrm{H}=-17.0 \mathrm{kcal} / \mathrm{mol}$

$\Delta S=-38.7$ e.u.

Fig. 8. Dependence of the association of $\mathbf{2 0}$ and $\mathbf{2 5 - 2 7}$ upon the protecting groups

dependence are evidenced. To obtain this information, we needed at least all dimers derived from $A$ and $U$. The rationalisation of the difficulty of obtaining ether-linked dimers derived from $\mathbf{1 0}$ suggested the preparation of thioethers. Modelling indicated that the thioether linkage does not significantly change the conformation of the oxymethylene-linked oligomers.

All dimers resulting from $\mathrm{S}$-alkylation of protected $5^{\prime}$-thio- $\mathrm{U}(*)$ and $5^{\prime}$-thio-A $(*)$ with the electrophiles 8 ( $\mathrm{Hal}=\mathrm{Br}$ or $\mathrm{OMs}$ ) and $10(\mathrm{R}=\mathrm{Br}$; Fig. 4) and their partially or fully deprotected derivatives $\mathbf{1 8}$ and 19 were prepared in 62-78\% yield (Fig. 6) [46].

The self-pairing O-isopropylideneprotected $\mathrm{U}^{*}$-[s]-A* silyl ether 20 (TDS = thexyldimethylsilyl) associates strongly in $\mathrm{CDCl}_{3}\left(K_{\text {ass }} 4000 \mathrm{M}^{-1}\right)$, the $\mathrm{U}^{*}-[\mathrm{s}]-\mathrm{U}^{*}$ analogue 21 associates with $K_{\text {ass }}=1000 \mathrm{~m}^{-1}$, while the corresponding $A *$-[s]-A* 22 does not associate (Fig. 7). A Job's plot showed a 1:1 stoichiometry for the pairing of $\mathbf{2 2}$ and 23. The concentration dependence of the chemical shift for $\mathrm{H}-\mathrm{C}(2)$ and $\mathrm{H}-\mathrm{C}(8)$ of 24 evidenced a Hoogsteen, or reverseHoogsteen hydrogen bonding; the crystalstructure analysis of $\mathbf{2 5}$ showed a reverseHoogsteen association.

The association constants depend strongly on the $\mathrm{C}(6 / \mathrm{I}$ or $8 / \mathrm{I})$ and $\mathrm{C}\left(5^{\prime} /\right.$ II) substituents, as illustrated by the association constants and thermodynamic parameters for the dimers 20 and 25-27 (Fig. 8). The difference of the $\Delta \mathrm{H}$ values means (in agreement with the $\Delta S$ values) that 20 forms six H-bonds (Hoogsteen type according to modelling) and the other three dimers only four of them. The intramolecular $\mathrm{H}$-bond between $\mathrm{C}\left(5^{\prime}\right) \mathrm{OH}$ and $\mathrm{C}(2)=\mathrm{O}$ entails a conformation that is incompatible with an intermolecular hydrogen bond of the $\mathrm{C}(8)$-hydroxymethyl group of $\mathbf{2 5}$. The strong association of $\mathbf{2 5}$ resulting from the favourable entropy of association suggested to check for stacking of the two bases. As shown in Fig. 9, one indeed finds the dependence of the absorption coefficient on temperature for 25 and 28 that evidences stacking of the nucleobases. This is not a trivial observation for a nucleotide dimer in chloroform solution, and strongly supports stacking and pairing of these analogues in chloroform.

The A*-[s]-U dimer 29 and the $\mathrm{A}^{*}$-[s]$\mathrm{U}^{*}$ dimer 30 gelate chloroform, dichloromethane, and ethyl acetate at a concentration between $0.4 \%$ and $1 \% \mathrm{wt} / \mathrm{vol}$ (Fig. 10). These gels are stable below $30{ }^{\circ} \mathrm{C}$, as determined by CD spectroscopy. SEM pictures revealed the formation of porous, lamellar structures. The propensity of these foldamers to form organogels (and perhaps hydrogels) deserves further attention, and is under scrutiny [47]. 
The strong dependence of the association strength upon the protecting groups of the hydroxymethyl substituents, and the presence of several conformations means that the structure of these dimers is not sufficiently well defined, and not well suited for a detailed study of the way in which they associate. Indeed, temperature-dependent ${ }^{1} \mathrm{H}-\mathrm{NMR}$ studies showed that the $\mathrm{U}^{*_{-}}[\mathrm{s}]-\mathrm{U}^{*}$ dimer 21 adopts at least two conformations. Longer oligomers appeared necessary, and we have so far synthesised the two self-associating tetramers $\mathrm{U}^{*_{-}}[\mathrm{s}]-\mathrm{A}^{*_{-}}[\mathrm{s}]-\mathrm{U}^{*}-[\mathrm{s}]-$ $\mathrm{A}^{*}(\mathbf{3 1})$ and $\mathrm{A}^{*}-[\mathrm{s}]-\mathrm{U}^{*}-[\mathrm{s}]-\mathrm{A}^{*}-[\mathrm{s}]-\mathrm{U}^{*}(\mathbf{3 2})$ (Fig. 11) according to the Scheme.

These tetramers strongly self-associate in $\mathrm{CDCl}_{3} / 5 \%$ DMSO $\left(K_{\text {ass }}\right.$ reaches $\left.6 \cdot 10^{5} \mathrm{M}^{-1}\right)$. Vapour pressure osmometry evidenced a 1:1 association, and ${ }^{1} \mathrm{H}-\mathrm{NMR}$ spectroscopy showed that $\mathbf{3 1}$ is conformationally homogeneous.

The structure of the duplex of $\mathbf{3 1}$ was elucidated using ${ }^{1} \mathrm{H}-\mathrm{NMR}$ spectroscopy (NOESY) and molecular modelling (Fig. 12) [48]. The duplex folds into a stable, unique structure (incipient right-handed A-type helix). The bases adopt a syn conformation, are stacked, and associate in a Watson-Crick mode.

The fully deprotected tetramers derived from $\mathbf{3 1}$ and $\mathbf{3 2}$ are well soluble in DMSO, but 'practically' insoluble in water (no UV absorption of the supernatant). This restricts the interest in these foldamers to applications in material sciences. We have started the synthesis of a cytidine- and guanosineincorporating octamer, to study a complete helix, and obtain more precise information about its structural parameters; we have also begun with the synthesis of close analogues that promise to be water soluble.

There were several reasons for re-examining the acetyleno-analogues: to show that more than one representative of the novel foldamers may pair and that there must be a family of such analogues, to access analogues with an all-carbon linker so as to determine the conformation of the linker in a duplex, and to test for the relevance of the syn/anti conformation of these acetylenoanalogues. Determination of the pairing of dimers and oligomers with a hydrogen bond to N(3) will allow the determination of whether association with the bases in an syn conformation is at all possible - there was no proof for the contention that an anti conformation is required for association. Reductive removal of the propargylic hydroxy group should allow these analogues to adopt an anti conformation, and lead to pairing.

For this reason, we prepared additional self-complementary, acetyleno-linked dimers and tetramers [44]. There is indeed a strong influence of the hydrogen bond to N(3) (Fig. 13). The self-complementary dimer $\mathbf{3 3}$ associates via only two (rather

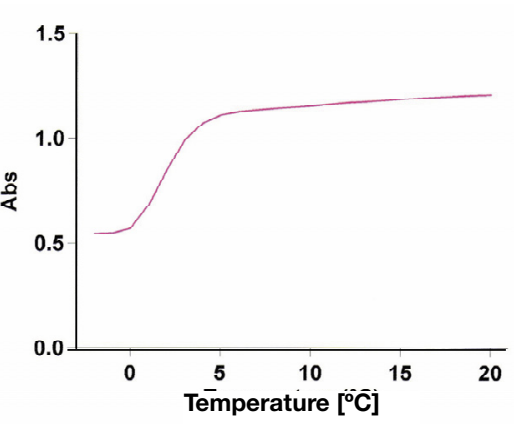

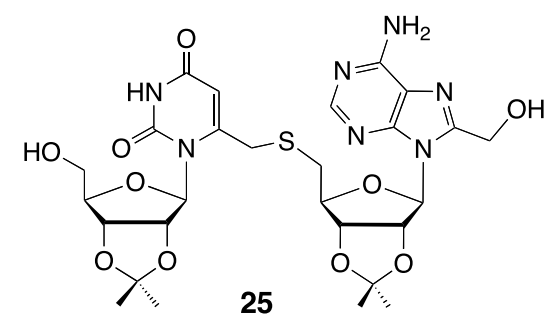
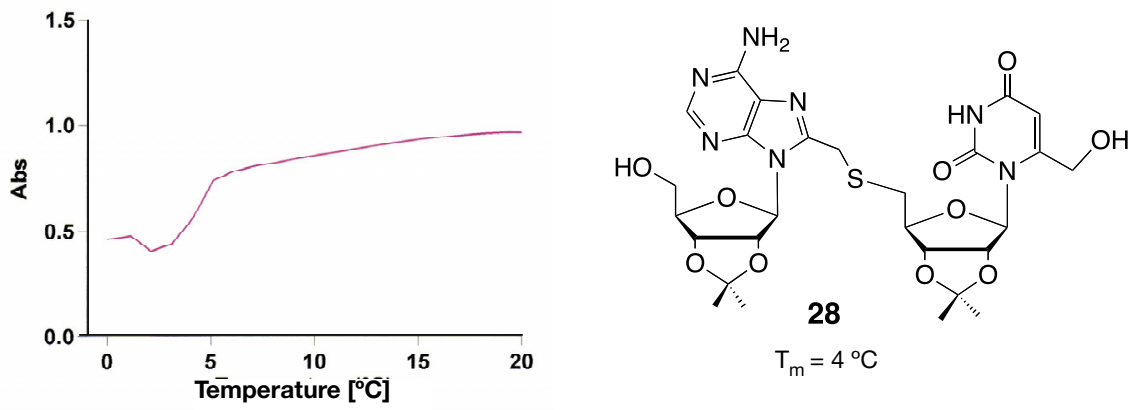

Fig. 9. Melting curve of the $U^{\star}-[s]-A^{*}$ dimer 25 and the $A^{*}-[s]-U^{\star}$ dimer 28 in chloroform $(c=21 \mu M)$
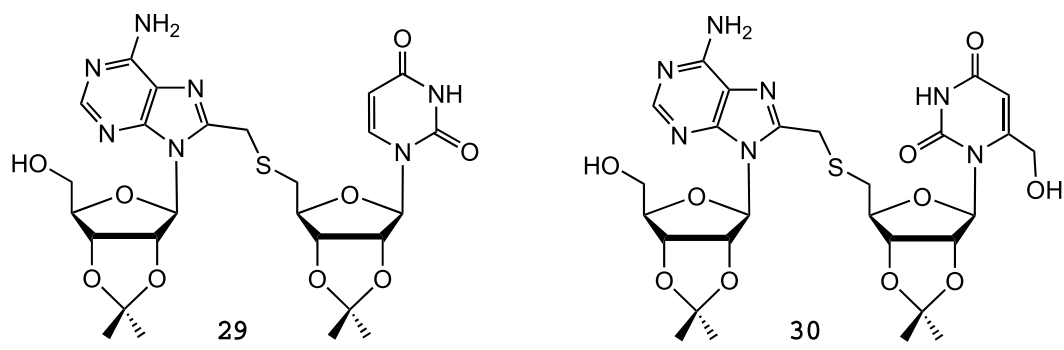

Fig. 10. The gelating $A^{*}-[s]-U$ dimer 29 and $A^{*}-[s]-U^{*}$ dimer 30

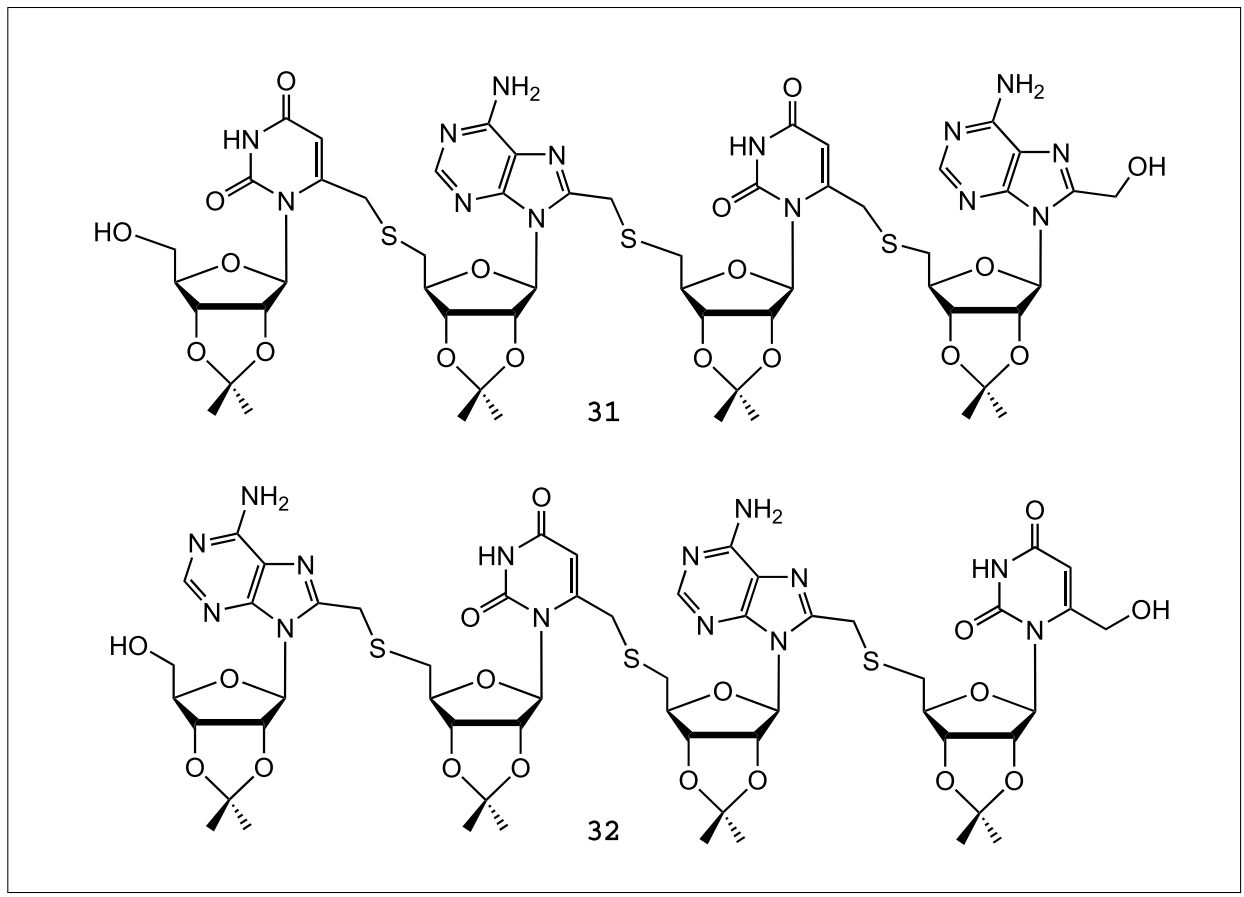

Fig. 11. The self-associating $U^{*}-[s]-A^{*}-[s]-U^{*}-[s]-A^{*}$ and $A^{*}-[s]-U^{*}-[s]-A^{*}-[s]-U^{*}$ tetramers 31 and 32 


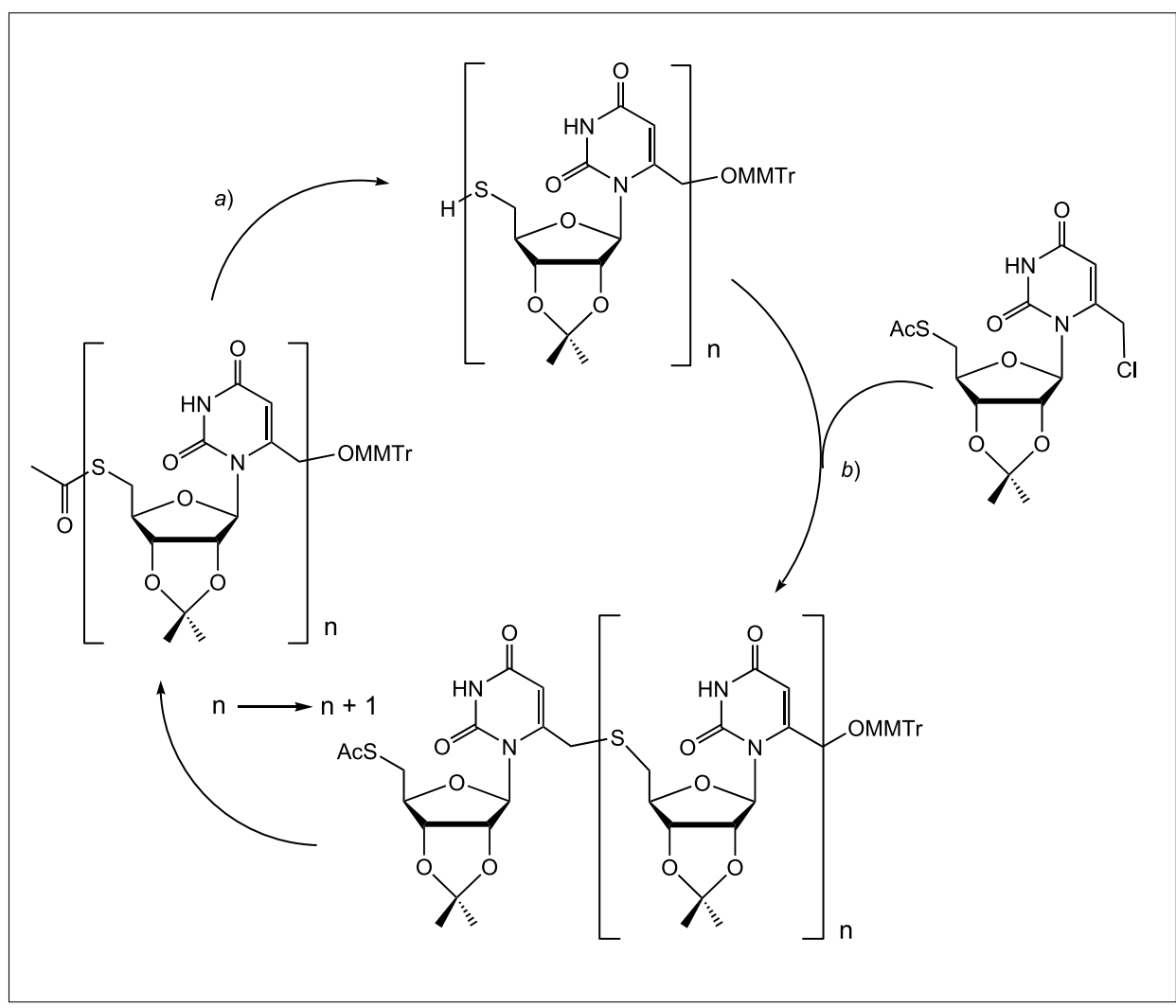

Scheme. a) Deprotonation with $\mathrm{K}_{2} \mathrm{CO}_{3}$ in $\mathrm{MeOH}$; b) coupling with $\mathrm{K}_{2} \mathrm{CO}_{3}$ in DMF

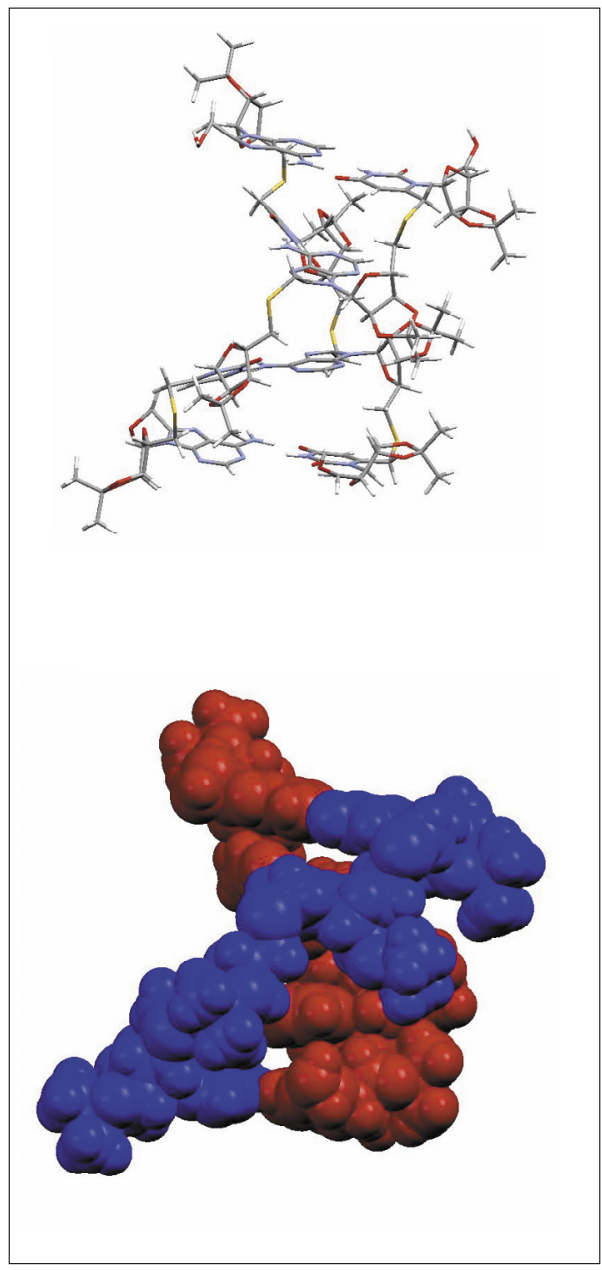

Fig. 12. Wire-frame and space-filling representation of the duplex $\mathbf{3 1}$ discussed below.
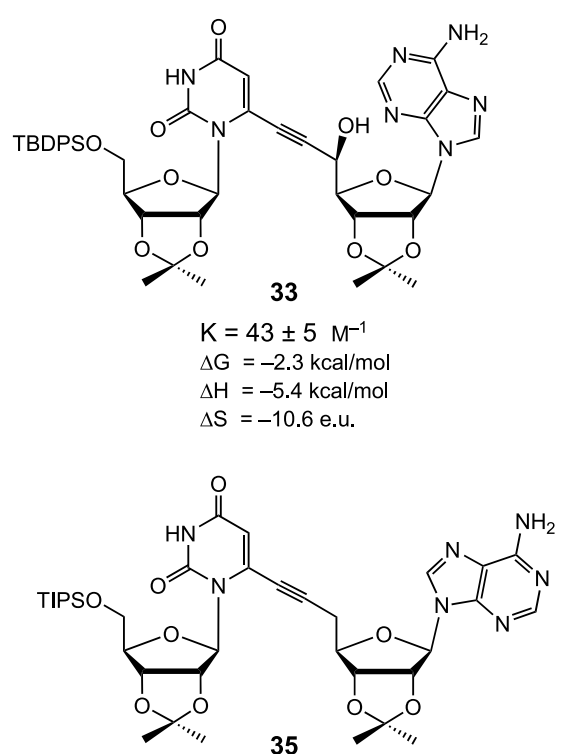

$\mathrm{K}=1159 \mathrm{M}^{-1}$

$\Delta \mathrm{G}=-4.2 \mathrm{kcal} / \mathrm{mol}$

$\Delta \mathrm{H}=-19.2 \mathrm{kcal} / \mathrm{mol}$

$\Delta S=-51.8$ e.u.
The $A *-[c]-U$ dimer 37 forms a gel in $\mathrm{CDCl}_{3}$ solution (Fig. 14). The solid-state structure of the closely related $\mathbf{3 8}$ is characterised by Watson-Crick and reverse-Hoogsteen hydrogen bonds.

The effect of the hydrogen bond to $\mathrm{N}(3)$ depends upon the position of the $\mathrm{A}^{*}$ residue, and is not much influenced by the hydrogen bond of the propargylic hydroxy group to $\mathrm{U}^{*}$, as evidenced by comparing the association of $\mathbf{3 9} v s . \mathbf{4 0}$ and of $\mathbf{4 1} v s . \mathbf{4 2}$ (Fig. 15).

Although these few comparisons show some regularity, the correlation between structure and association of these and additional self-complementary dimers is not straightforward. The low value of the enthalpy of association for $33(\Delta \mathrm{H}=-5.4 \mathrm{kcal} /$ mol) suggests association via two weak hydrogen bonds, and no contribution from stacking, while 39 and 41 ( $\Delta \mathrm{H}$ of -12 to $-13 \mathrm{kcal} / \mathrm{mol}$ ) appear to associate via four slightly stronger hydrogen bonds, again without any contribution from stacking. The deoxy dimers 35 and $\mathbf{3 6}(\Delta \mathrm{H} c a .-20$ $\mathrm{kcal} / \mathrm{mol}$ ) must associate via four hydrogen bonds (more are not possible), and the high enthalpy value suggests that base stacking contributes to association. A model (33A; for modelling TBDPSO was replaced by a $\mathrm{Me}_{3} \mathrm{SiO}$ group) of the $\mathrm{U}^{*}-[\mathrm{c}]-\mathrm{A}$ dimer 33 (Fig. 13) is shown in Fig. 16. Only two intermolecular hydrogen bonds can be formed in the presence of the intramolecular hydrogen bond from the propargylic $\mathrm{OH}$ to N(3) of the adenine moiety. Four intermolecular hydrogen bonds for 33B can only be formed at the expense of this intramo-

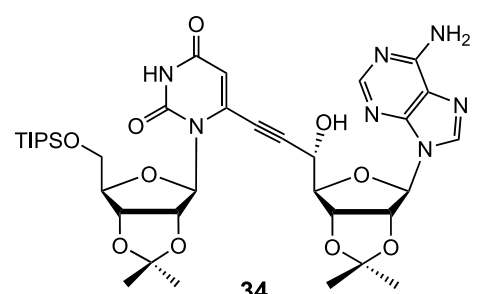

$\mathrm{K}=138 \pm 5 \mathrm{M}^{-1}$

$\Delta \mathrm{G}=-2.9 \mathrm{kcal} / \mathrm{mo}$ $\Delta \mathrm{H}=-10.6 \mathrm{kcal} / \mathrm{mol}$ $\Delta S=-26.0$ e.u.

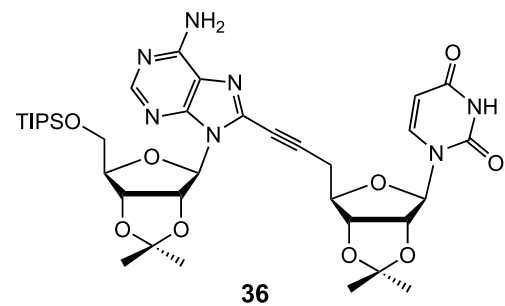

$\mathrm{K}=277 \pm 5 \mathrm{M}^{-1}$

$\Delta \mathrm{G}=-3.8 \mathrm{kcal} / \mathrm{mol}$ $\Delta \mathrm{H}=-21.7 \mathrm{kcal} / \mathrm{mol}$ $\Delta S=-60.9$ e.u 
a)

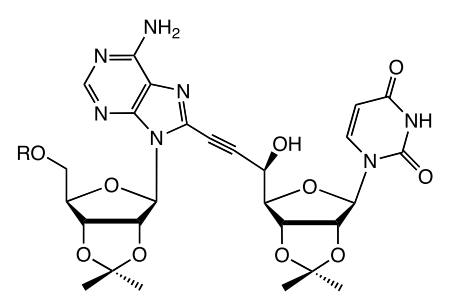

$37 \mathrm{R}=\mathrm{Sit}^{-}-\mathrm{BuMe}_{2}$

$38 \mathrm{R}=\mathrm{Sit}_{\mathrm{B}} \mathrm{BuPh}_{2}$

b)
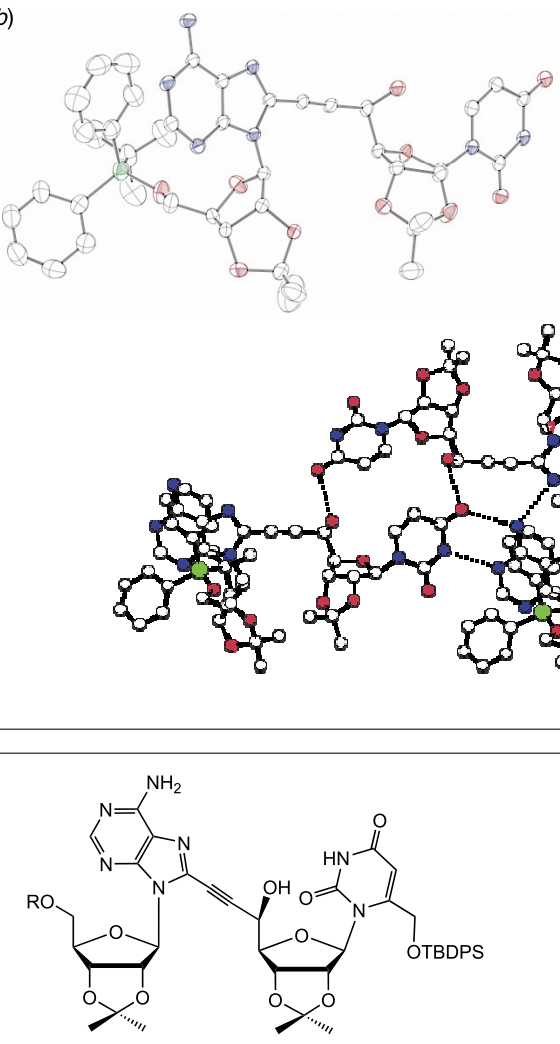

$\mathrm{K}=1793 \pm 5 \mathrm{M}^{-1}$
$39 \mathrm{R}=$ TIPS

$\mathrm{K}=364 \pm 5 \mathrm{M}^{-1}$

$\Delta \mathrm{G}=-3.4 \mathrm{kcal} / \mathrm{mol}$

$\Delta \mathrm{H}=-12.1 \mathrm{kcal} / \mathrm{mol}$

$\Delta \mathrm{S}=-29.3$ e.u.

\begin{abstract}
$40 \mathrm{R}=\mathrm{H}$
\end{abstract}
$\mathrm{K}=232 \pm 5 \mathrm{M}^{-1}$ $\Delta G=-3.2 \mathrm{kcal} / \mathrm{mol}$ $\Delta \mathrm{H}=-34.2 \mathrm{kcal} / \mathrm{mo}$ $\Delta S=-104.9$ e.u.
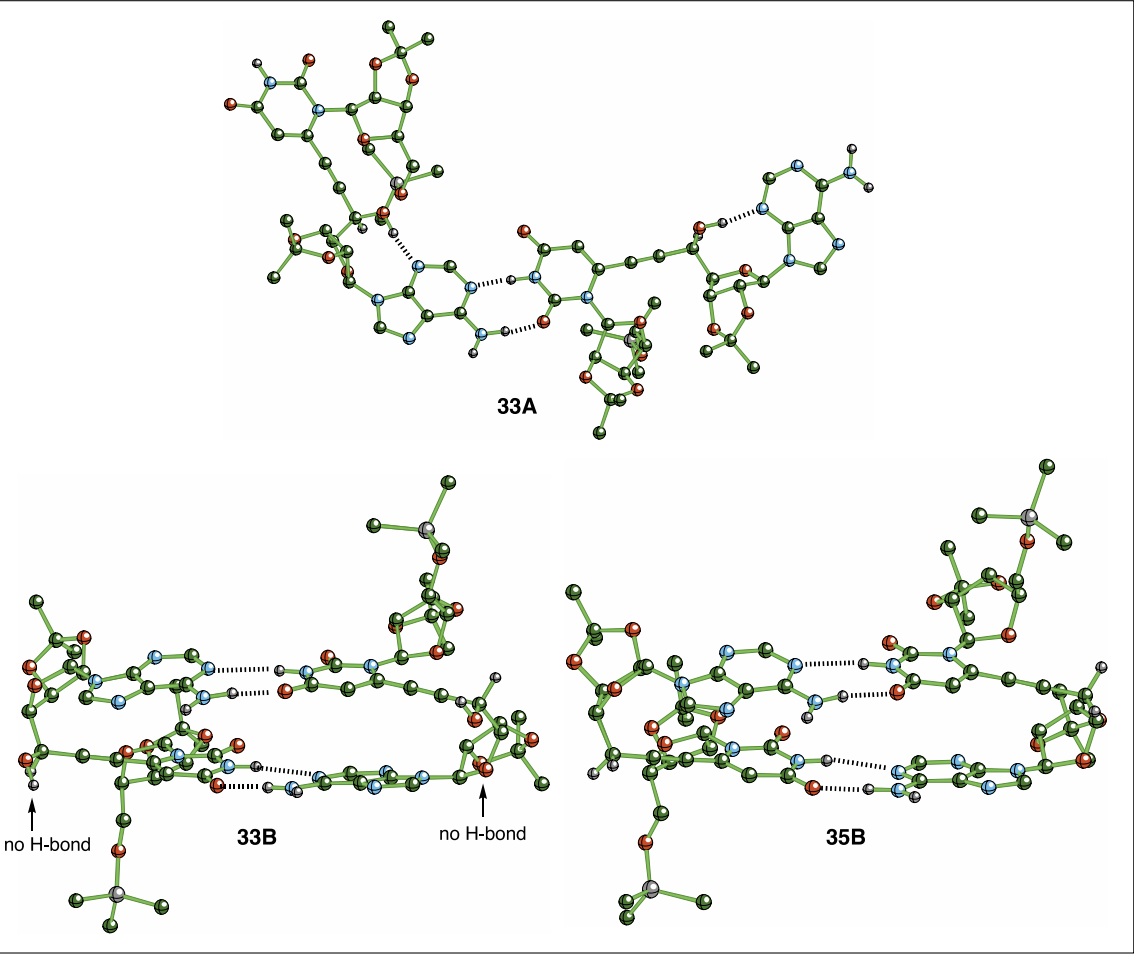

Fig. 14. a) $A^{*}-[c]-U$-dimers 37 and 38 , and b) crystal structure of $\mathbf{3 8}$

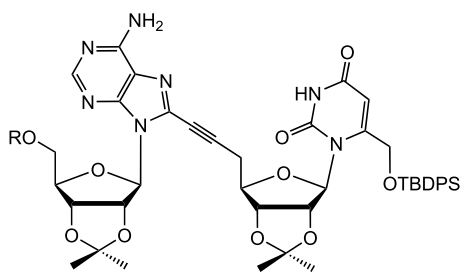

$41 \mathrm{R}=\mathrm{TIPS}$ $\Delta \mathrm{G}=-4.2 \mathrm{kcal} / \mathrm{mo}$ $\Delta \mathrm{H}=-13.2 \mathrm{kcal} / \mathrm{mo}$ $\Delta \mathrm{S}=-30.5 \mathrm{e} \cdot \mathrm{u}$
$\mathrm{R}=\mathrm{H}$ $\Delta \mathrm{G}=-4.9 \mathrm{kcal} / \mathrm{mo}$ $\Delta S=-63.6$ e.u.
Fig. 16. Models of $\mathbf{3 3}$ and $\mathbf{3 5}$ : association via two and four hydrogen bonds, and the influence of the intramolecular hydrogen bond to $\mathrm{N}(3)$ 
lecular hydrogen bond; there is no similar penalty for $\mathbf{3 5}$, as shown by the model of its duplex 35B featuring four hydrogen bonds and base stacking.

A clear dependence of the association upon the sequence is also evident by comparing the association in $\mathrm{CHCl}_{3} / \mathrm{DMSO} 1: 4$ of the four tetramers $\mathbf{4 3 - 4 6}$ (Fig. 17); only two of them associate.

Reduction of the triple bond gave the desired propanylene-linked dimers $\mathbf{4 7}$ and $\mathbf{4 8}$ (Fig. 18); they associate only weakly so that the desired conformational analysis was not feasible. Surprisingly, the $(Z)$-alkene analogues $49(\Delta \mathrm{G}=-3.5 \mathrm{kcal} / \mathrm{mol})$ and $50(\Delta \mathrm{G}$ $=-5.1 \mathrm{kcal} / \mathrm{mol})$ pair significantly more strongly; the $(E)$ isomer of $\mathbf{5 0}$ pairs about as strongly as the saturated $\mathbf{4 8}$.

\section{Outlook}

These findings evidence that pairing by the thioethers is not a singular case, and that there must be (many) more representatives of this novel type of baseintegrating oligonucleotide analogues. It should be possible to tune the structure of duplexes and the strength of the association, and to shape secondary structural elements. It is obvious that we are only at the beginning. The immediate goals pursued by the group are the incorporation of cytidine and guanosine monomers, the synthesis of octamers, and of water-soluble analogues.

\section{Acknowledgements}

I thank the ETH Zürich and Hoffmann-La Roche AG for generous support, Zeena Johar and Prof. Bernhard Jaun for the determination of the conformation of the thiomethylenebridged tetramer, Michael Stalder for the SEM pictures of the gels, Dr. Thomas Schweizer for the determination of their rheological properties, and all members of the group, particularly Dr. Bruno Bernet, for their continuous stimulating enthusiasm.

Received: August 17, 2005

[1] M. Koizumi, Biol. Pharm. Bull. 2004, 27, 453.

[2] N.V. Sumbatyan, V.A. Mandrugin, A. Deroussent, R.-R. Bertrand, Z. Majer, C. Malvy, G.A. Korshunova, M. Hollosi, M.B. Gottikh, Nucleos. Nucleot. Nucleic Acids 2004, 23, 1911.

[3] F. Eckstein, in 'Nucleic Acid Therapeutics in Cancer', Ed. A.M. Gewirtz, Humana Press, Totowa, New Jersey, 2004, p. 3.

[4] S.T. Crooke, Annu. Rev. Med. 2004, 55, 61.

[5] M. Rubenstein, P. Tsui, P. Guinan, Drugs Future 2004, 29, 893.

[6] P. Gu, G. Schepers, J. Rozenski, A. Van Aerschot, P. Herdewijn, Oligonucleotides 2003, 13, 479 .

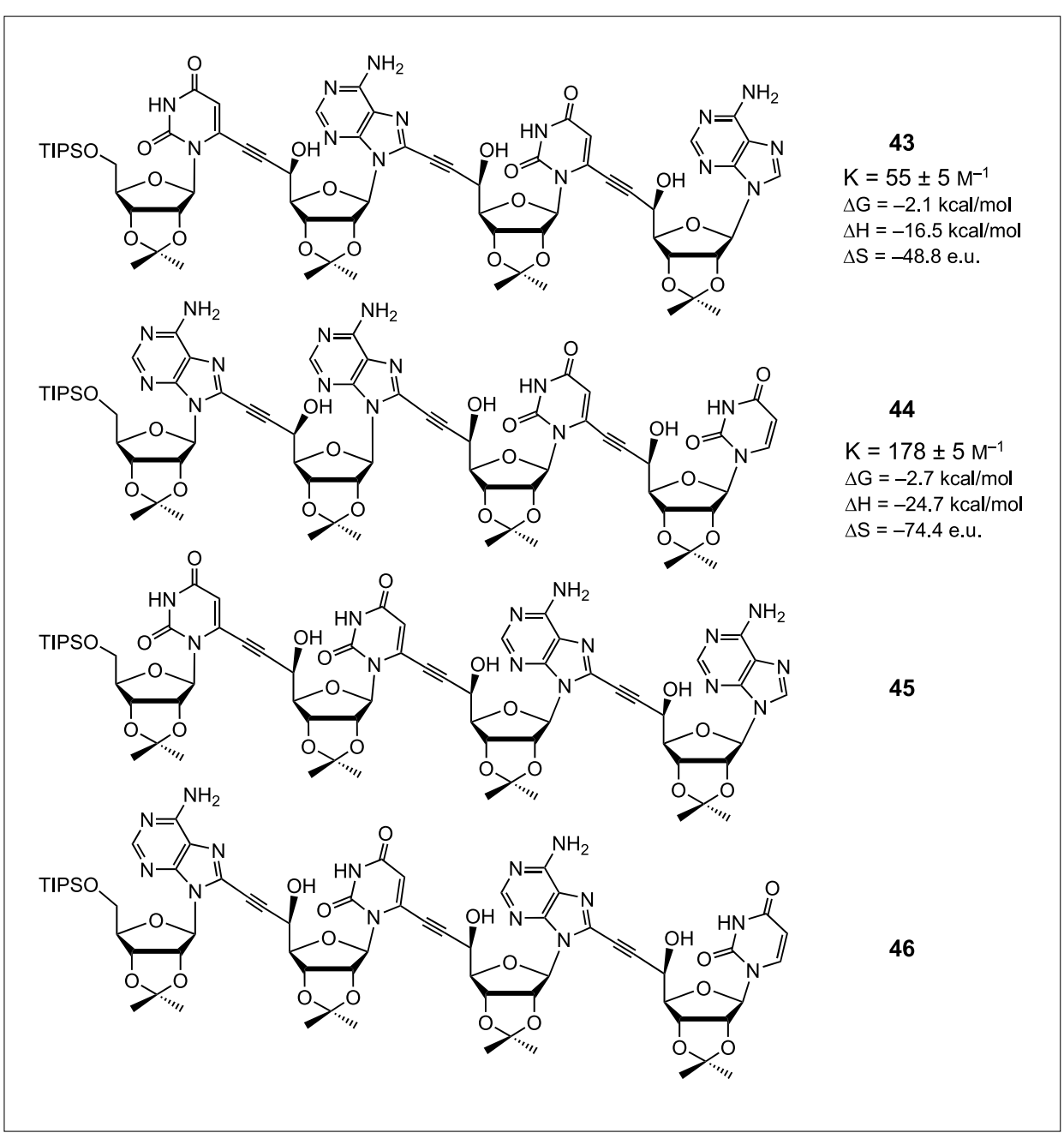

Fig. 17. Association of self-complementary tetramers $43-46$
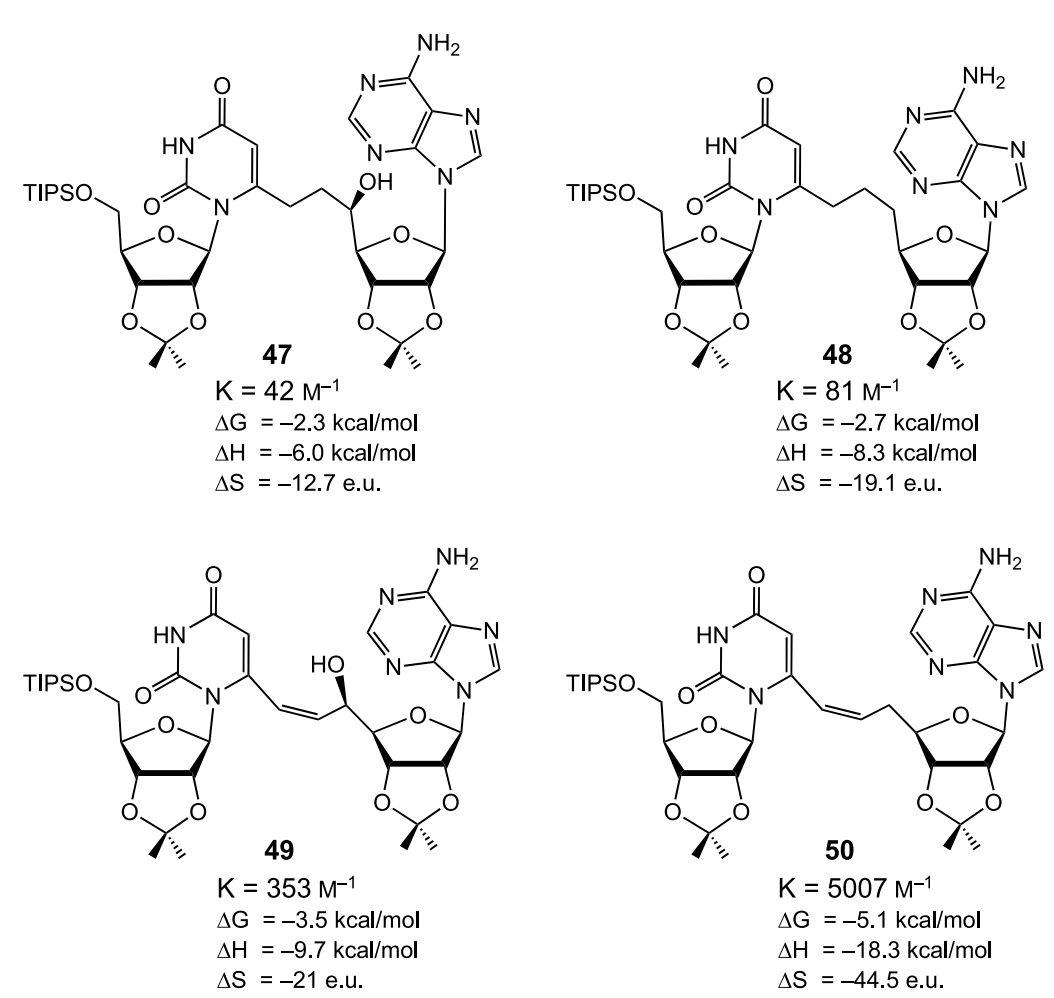

Fig. 18. Propanylene- and (Z)-propenylene-linked dimers 47-50 
[7] Y.L. Ding, Q. Habib, S.Z. Shaw, D.Y. Li, J.W. Abt, Z. Hong, H.Y. An, J. Comb Chem. 2003, 5, 851.

[8] Y.S. Cho-Chung, A.M. Gewirtz, C.A. Stein, 'Therapeutic Oligonucleotides. Antisense, RNAi, Triple-Helix, Gene Repair, Enhancer Decoys, CpG, and DNA Chips', The New York Academy of Sciences, New York, 2003, 1002.

[9] M. Pooga, T. Land, T. Bartfai, Ü. Langel, Biomol. Eng. 2001, 17, 183.

[10] J. Micklefield, Curr. Med. Chem. 2001, 8, 1157.

[11] R. Morishita, M. Aoki, Y. Kaneda, Anal. N.Y. Acad. Sci. 2001, 947, 294.

[12] C.R. Noe, L. Kaufhold, in 'New Trends in Synthetic Medicinal Chemistry', Ed. F. Gualtieri, Wiley-VCH, Weinheim, 2000, p. 261.

[13] C. Hélène, in 'Triple Helix Forming Oligonucleotides', Eds. C. Malvy, A. HarelBellan. L.L. Pritchard, Kluwer Academic Publishers, Boston, 1999, p. 3.

[14] P.H. Seeberger, M.H. Caruthers, in 'Applied Antisense Oligonucleotide Technology', Eds. C.A. Stein, A. M. Krieg, Wiley-Liss, New York, 1998, p. 51.

[15] M. Ferencic, G. Reddy, X. Wu, J. Nandy, R. Krishnamurthy, A. Eschenmoser, Chem. Biodiv. 2004, 1, 939; A. Eschenmoser, Origins Life Evol. Biosphere 2004, 34, 277; K.-U. Schöning, P. Scholz, S. Guntha, X. Wu, R. Krishnamurthy, A. Eschenmoser, Science 2000, 290, 1347; A. Eschenmoser, R. Krishnamurthy, Pure Appl. Chem. 2000, 72, 343; A. Eschenmoser, Science 1999, 284, 2118; A. Eschenmoser, Nucleos. Nucleot. 1999, 18, 1363; M. Beier, F. Reck, T. Wagner, R. Krishnamurthy, A. Eschenmoser, Science 1999, 283, 699; A. Eschenmoser, Origins Life Evol. Biosphere 1997, 27, 535; M. Bolli, R. Micura, A. Eschenmoser, Chem. Biol. 1997, 4, 309; A. Eschenmoser, Origins Life Evol. Biosphere 1994, 24, 389; S. Pitsch, S. Wendeborn, B. Jaun, A. Eschenmoser, Helv. Chim. Acta 1993, 76, 2161; A. Eschenmoser, E. Loewenthal, Chem. Soc. Rev. 1992, 21, 1; A. Eschenmoser, M. Dobler, Helv. Chim. Acta 1992, 75, 218.

[16] M. Hollenstein, C.J. Leumann, J. Org. Chem. 2005, 70, 3205.

[17] I. Dilek, M. Madrid, R. Singh, C.P. Urrea, B.A. Armitage, J. Am. Chem. Soc. 2005, 127, 3339; B. Datta, M.E. Bier, S. Roy, B.A. Armitage, J. Am. Chem. Soc. 2005, 127, 4199

[18] T. Da Ros, G. Spalluto, M. Prato, T. Saison-Behmoaras, A. Boutorine, B. Cacciari, Curr. Med. Chem. 2005, 12, 71.

[19] T. Govindaraju, V.A. Kumar, K.N. Ganesh, J. Org. Chem. 2004, 69, 1858; P.S. Lonkar, K.N. Ganesh, V.A. Kumar, Org. Biomol. Chem. 2004, 2, 2604.

[20] P.E. Nielsen, Mol. Biotechnol. 2004, 26, 233.

[21] M. Myers, J.K. Pokorski, D.H. Appella, Org. Lett. 2004, 6, 4699.
[22] P. Lukeman, A.C. Mittal, N.C. Seeman, Chem. Commun. 2004, 1694.

[23] Y. Huang, S. Dey, X. Zhang, F. Sönnichsen, P. Garner, J. Am. Chem. Soc. 2004, 126, 4626 .

[24] D. Baulcombe, Pflanzenschutz-Nachrichten Bayer 2005, 58, 21

[25] H. Gong, C.-M. Liu, D.-P. Liu, C.-C. Liang, Med. Res. Rev. 2005, 25, 361 .

[26] P.C. Anderson, S. Mecozzi, J. Am. Chem. Soc. 2005, 127, 5290.

[27] C.R. Allerson, N. Sioufi, R. Jarres, T.P. Prakash, N. Naik, A. Berdeja, L. Wanders, R.H. Grifey, E.E. Swayze, B. Bhat, J. Med. Chem. 2005, 48, 901.

[28] S. Vijgen, K. Nauwelaerts, J. Wang, A. Van Aerschot, I. Lagoja, P. Herdewijn, $J$. Org. Chem. 2005, 70, 4591.

[29] C.D. Novina, P.A. Sharp, Nature 2004, 430, 161; D.M. Dykxhoorn, C.D. Novina, P.A. Sharp, Nat. Rev. 2003, 4, 456.

[30] R.R. Breaker, Nature 2004, 432, 838.

[31] S. Eppacher, N. Solladié, B. Bernet, A. Vasella, Helv. Chim. Acta 2000, 83, 1311.

[32] N.C. Seeman, Trends Biochem. Sci. 2005, 30, 119; W. Shen, M.F. Bruist, S.D. Goodman, N.C. Seeman, Angew. Chem. Int. Ed. 2004, 43, 4750; N.C. Seeman, Nature 2003, 421, 427 .

[33] B. Samori, G. Zuccheri, Angew. Chem. Int. Ed. 2005, 44, 1166.

[34] P. Hazarika, B. Ceyhan, C.M. Niemeyer, Angew. Chem. Int. Ed. 2004, 43, 6469; C.M. Niemeyer, M. Adler, Angew. Chem. Int. Ed. 2002, 41, 3779; C.M. Niemeyer, Angew. Chem. Int. Ed. 2001, 40, 4128.

[35] K.V. Gothelf, A. Thomson, M. Nielsen, E. Ciò, R.S. Brown, J. Am. Chem. Soc. 2004 , 126, 1044

[36] V.V. Demidov, M.D. Frank-Kamenetskii, Trends Biochem. Sci. 2004, 29, 62

[37] R. Rinaldi, E. Branca, R. Cingolani, S. Masiero, G.P. Spada, G. Gottarelli, Appl. Phys. Lett. 2001, 78, 3541.

[38] J.M. Ryter, S.C. Schultz, EMBO J. 1998, 17, 7505.

[39] W. Czechtizky, X. Daura, A. Vasella, W. van Gunsteren, Helv. Chim. Acta 2001, 84, 2132; W. Czechtizky, A. Vasella, Helv. Chim. Acta 2001, 84, 1000; W. Czechtizky, A. Vasella, Helv. Chim. Acta 2001, 84, 594; W. Czechtizki, Ph. D. Thesis ETH Zürich No. 14239, 2001.

[40] H. Gunji, A. Vasella, Helv. Chim. Acta 2000, 83, 3229; H. Gunji, A. Vasella, Helv. Chim. Acta 2000, 83, 2975; H. Gunji, A. Vasella, Helv. Chim. Acta 2000, 83, 1331.

[41] S. Eppacher, P.K. Bhardwaj, B. Bernet, J.L.B. Gala, T. Knöpfel, A. Vasella, Helv. Chim. Acta 2004, 87, 2969.

[42] S. Eppacher, N. Solladié, A. Vasella, Helv. Chim. Acta 2004, 87, 2926; S. Eppacher, Ph. D. Thesis ETH Zürich No. 15088, 2003

[43] P.K. Bhardwaj, A. Vasella, Helv. Chim. Acta 2002, 85, 699.

[44] X. Zhang, A. Vasella, in preparation.

[45] A.J. Matthews, P.K. Bhardwaj, A. Vasella, Helv. Chim. Acta 2004, 87, 2273; A.J.
Matthews, P.K. Bhardwaj, A. Vasella, Chem. Commun. 2003, 950.

[46] A. Viger, A. Vasella, in preparation; A. Viger, Ph. D. Thesis ETH Zürich No. 16060, 2005.

[47] A. Viger, S. Hebbe, A. Vasella, in preparation.

[48] A. Viger, Z. Johar, B. Jaun, A. Vasella, in preparation. 